\title{
NOTES
}

\section{Amorphous Supermolecular Structure of High-Speed-Spun Poly(ethylene terephthalate) Fibers as Revealed by Temperature Dependence of Viscoelastic Properties}

\author{
Kenji Kamide, Sei-ichi Manabe, and Tomio KurIKI \\ Fundamental Research Laboratory of Fiber and Fiber-Forming Polymers, \\ Asahi Chemical Industry Co., Ltd., 11-7 Hacchonawate, \\ Takatsuki, Osaka 569, Japan
}

(Received July 4, 1985)

\begin{abstract}
KEY WORDS Amorphous Region / Supermolecular Structure / Poly(ethylene terephthalate) / Viscoelasticity / Dynamic Loss Tangent / High Speed Spinning /
\end{abstract}

High speed spinning of poly(ethylene terephthalate) (PET, poly(oxyethyleneoxyterephthaloyl)) fibers should have a great economical merit enabling us to omit the drawing operation. The study on high speed spinning of PET fibers has discussed the relationships among the spinning conditions, crystallinity, degree of orientation, and mechanical properties of as-spun fiber. ${ }^{1}$ It has been clarified that the amorphous region of regenerated cellulose and synthetic fibers is closely correlated to chemical reactivity, ${ }^{2}$ dyeability, ${ }^{3-6}$ swelling property, ${ }^{7}$ absorbing power of gas ${ }^{8}$ and breaking extension. ${ }^{2}$ In this sense, it is highly desirable to investigate the amorphous supermolecular structure of high speed spun PET fibers. This motivated us to evaluate the amorphous supermolecular structure by applying Manabe, Kamide et al.'s theory ${ }^{9-13}$ to the temperature dependence of dynamic viscoelasticity of high speed spun PET fibers, and to clarify their structural characteristics. Various PET fibers were prepared by changing the spinning velocity alone and keeping other conditions constant.

\section{EXPERIMENTAL}

\section{Polymer}

PET chips, with carboxyl group content of $30 \mathrm{meq} \mathrm{kg}^{-1}$ and limiting viscosity number $[\eta]$ of $73 \mathrm{~cm}^{3} \mathrm{~g}^{-1}$ in a phenol/tetrachlorethane mixture $(1 / 2, \mathrm{w} / \mathrm{w})$ at $25^{\circ} \mathrm{C}$ (i.e., the viscosityaverage molecular weight $M_{v}=4.4 \times 10^{4}$, calculated using the Mark-Houwink-Sakurada equation established by Kamide et al. ${ }^{14}$ ), were synthesized in our laboratory and used for further study.

\section{Melt Spinning}

The PET chips were melt extruded at $300^{\circ} \mathrm{C}$ through a die having four holes with $0.5 \mathrm{~mm}$ in diameter and $1.0 \mathrm{~mm}$ in length at a flow rate of $16 \mathrm{~g} \mathrm{~min}^{-1}$ and were wound with a spinning velocity ranging from 2 to $9 \mathrm{~km} \mathrm{~min}^{-1}$. Here, the spinning velocity $V_{\mathrm{s}}$ was defined as the surface velocity of the rotating winder in the wind-up machine.

\section{RESULTS AND DISCUSSION}

Figure 1 shows the temperature dependence of dynamic modulus $E^{\prime}$ and dynamic mechanical loss tangent $\tan \delta$ measured at a frequency 


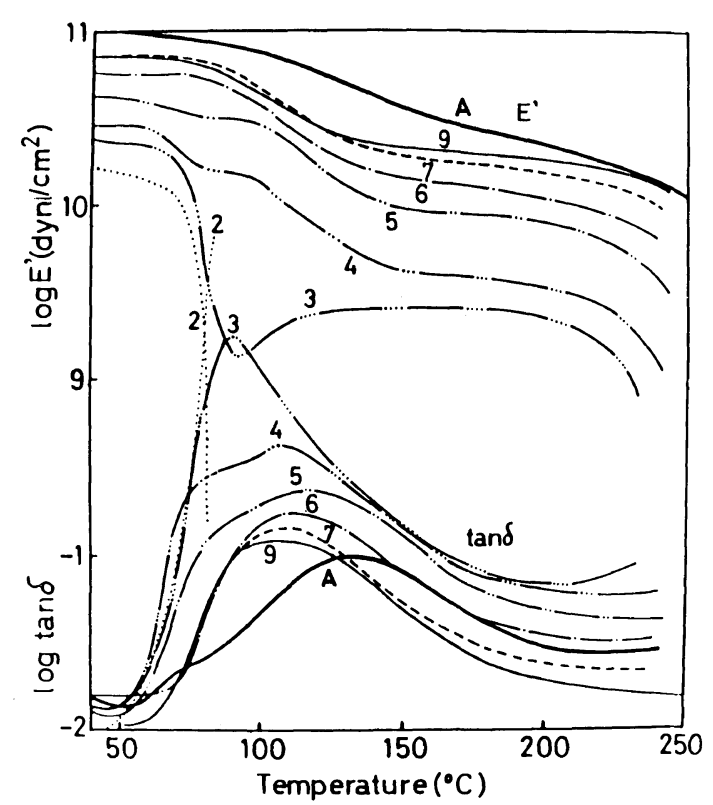

Figure 1. Temperature dependence of the dynamic modulus $\left(E^{\prime}\right)$ and dynamic loss tangent $(\tan \delta)$ of asspun PET fibers: measuring frequency, $110 \mathrm{~Hz}$; The number on the curve denotes the spinning velocity $V_{\mathrm{s}}$ in $\mathrm{km} \mathrm{min}{ }^{-1}$ and $\mathrm{A}$ indicates commercially available drawn fibers produced by a conventional method $\left(V_{\mathrm{s}}=\right.$ $1.5 \mathrm{~km} \mathrm{~min}^{-1}$, draw temperature $130^{\circ} \mathrm{C}$, draw ratio 3.9 ).

of $110 \mathrm{~Hz}$ for as-spun PET fibers. The figure also includes the data point of a conventional fiber, denoted by A, spun at a speed of $1.5 \mathrm{~km}$ $\min ^{-1}$ and thereafter drawn at $130^{\circ} \mathrm{C}$ with a draw ratio of 3.9 using a hot pin type draw twister. The crystallinity and crystal orientation at the peripheral of the fiber (skin part) spun at $V_{\mathrm{s}}>5 \mathrm{~km} \mathrm{~min}^{-1}$ are larger than those of the inner part (core part) ${ }^{15}$. The contribution of the skin part to the mean value of the viscoelasticities such as $\tan \delta$ and $E^{\prime}$ is small and is negligible, when the mean value is concerned with the peak values of $\tan \delta$, $(\tan \delta)_{\max }$, and temperature, $T_{\max }$.

In the range $50-200^{\circ} \mathrm{C}$, the $\tan \delta$-temperature curve exibits a peak and $E^{\prime}$ decreases significantly, corresponding to the appearance of the $\tan \delta$ peak. As $V_{\mathrm{s}}$ increases, the $\tan \delta$ peak height decreases and $E^{\prime}$ increases. As-spun PET fibers spun at $V_{\mathrm{s}}$ of $2 \mathrm{~km} \mathrm{~min}^{-1}$

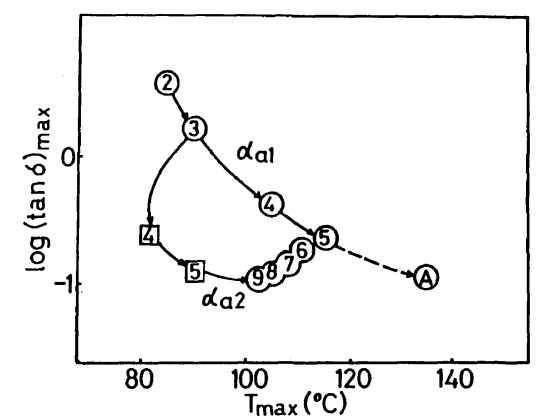

Figure 2. Change in the peak value of $\tan \delta,(\tan \delta)_{\max }$ and $T_{\max }$ with the spinning velocity $V_{\mathrm{s}}$ for as-spun PET fibers. The numbers denote $V_{\mathrm{s}}$ in $\mathrm{km} \mathrm{min}^{-1}$ and $\mathrm{A}$ has the same denotation as that in Figure 1. The circle and square denote the peak and shoulder, respectively.

begin to shrink remarkably as early as at $80^{\circ} \mathrm{C}$. For as-spun PET fibers at $V_{\mathrm{s}}$ of $3 \mathrm{~km} \mathrm{~min}^{-1}, E^{\prime}$ decreases drastically with an increase in the temperature up to $90^{\circ} \mathrm{C}$ and then gradually increases above $90^{\circ} \mathrm{C}$ and below $200^{\circ} \mathrm{C}$ after passing a minimun at $90^{\circ} \mathrm{C}$. This gradual increase is reasonably attributable to cold crystallization during the measurement at 90 $120^{\circ} \mathrm{C}$. Tan $\delta$-temperature curves of as-spun PET fibers at $V_{\mathrm{s}}$ of 4 and $5 \mathrm{~km} \mathrm{~min}^{-1}$ show a small peak or shoulder at $c a .70^{\circ} \mathrm{C}$ besides a main peak and $E^{\prime}$ decrease stepwisely, corresponding to the appearance of two mechanical absorptions (one peak and one shoulder) in the $\tan \delta$-temperature curve.

Figure 2 shows the plot of logarithm of $(\tan \delta)_{\max }$ and $T_{\max }$. The number in the circle (which represents the $\tan \delta$ peak) and in the square (shoulder) means $V_{\mathrm{s}}$ (in the unit of $\mathrm{km} \mathrm{min}^{-1}$ ) and $\mathrm{A}$ is the commercially available PET fiber, produced by the conventional method as described above.

With an increase in $V_{\mathrm{s}},(\tan \delta)_{\max }$ decreases monotonously, but $T_{\max }$ attains maximum at $V_{\mathrm{s}}=5 \mathrm{~km} \mathrm{~min}^{-1}$. In other words, in the range of $V_{\mathrm{s}}=2-5 \mathrm{~km} \mathrm{~min}^{-1}$, the plot of $(\tan \delta)_{\max }$ vs. $T_{\max }$ falls in a single convex downward curve, indicating $(\tan \delta)_{\max }$ to decrease and $T_{\max }$ to shift to the higher temperature region with an increase in $V_{\mathrm{s}}$. The corresponding point of the commercial PET fiber lies on the 


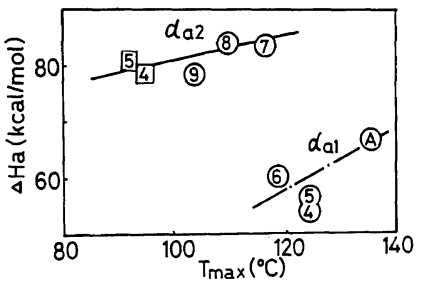

Figure 3. Plot of apparent activation energy $\Delta H_{\mathrm{a}}$ as a function of $T_{\max }$ for as-spun PET fibers: The number, A, circle and square have the same denotations as in Figures 1 and 2 .

extrapolated curve of the single downward curve. On the other hands, the data points for $V_{\mathrm{s}}=5-9 \mathrm{~km} \mathrm{~min}^{-1}$ make another curve. As $V_{\mathrm{s}}$ increases beyond $5 \mathrm{~km} \mathrm{~min}^{-1},(\tan \delta)_{\max }$ decreases and $T_{\max }$ shifts to lower temperature. The shoulder in the $\tan \delta$-temperature curve for as-spun PET fibers at $V_{\mathrm{s}}=4$ $5 \mathrm{~km} \mathrm{~min}^{-1}$ seems to lie on the extrapolated line of the points for $V_{\mathrm{s}}=6-9 \mathrm{~km} \mathrm{~min}^{-1}$.

Figure 3 shows the relation between the apparent activation energy $\Delta H_{\mathrm{a}}$, evaluated by measuring frequency $\mathrm{f}$ dependence of $T_{\max }$, and $T_{\max }$. In the figure, the number in the circle (peak) and in the square (shoulder) denotes $V_{\mathrm{s}}$ in $\mathrm{km} \mathrm{min}^{-1}$ and $\mathrm{A}$ has the same denotation as that in Figures 1 and 2. The $\Delta H_{\mathrm{a}}$ can be roughly classified into two categories: $\Delta H_{\mathrm{a}}=60 \pm 5 \mathrm{kcal} \mathrm{mol}^{-1}$ for the main $\tan \delta$ peak of as-spun PET fibers at $V_{\mathrm{s}} \leqq 6 \mathrm{~km} \mathrm{~min}^{-1}$ and $\Delta H_{\mathrm{a}}=80 \pm 5 \mathrm{kcal} \mathrm{mol}^{-1}$ for as-spun PET fibers at $V_{\mathrm{s}} \geqq 7 \mathrm{~km} \mathrm{~min}^{-1}$ and also for the small shoulder of $\tan \delta$ of as-spun PET fibers at $V_{\mathrm{s}}=4-5 \mathrm{~km} \mathrm{~min}^{-1}$. Note that there exists a dramatic change in $\Delta H_{\mathrm{a}}$ of the main $\tan \delta$ peaks between $V_{\mathrm{s}}=6$ and $7 \mathrm{~km} \mathrm{~min}^{-1}$. These two values of $\Delta H_{\mathrm{a}}$ can be attributed to the microbrownian movement of the main chains belonging to two amorphous regions with supermolecular structures different from each other. We refer to these dispersions from the higher temperature side, as $\alpha_{\mathrm{a} 1}$ and $\alpha_{\mathrm{a} 2}$, respectively. Here, it should be noted that $\Delta H_{\mathrm{a}}$ in Figure 3 was estimated for the main peak and shoulder of $\tan \delta$-temperature curve. The $\tan \delta$-temperature curve carefully obtained at a lower frequency indicated that a small, but not negligible amount of the amorphous region having $\Delta H_{\mathrm{a}}$ different from that of the main peak coexisted for as-spun fibers spun at $V_{\mathrm{s}}=6-9 \mathrm{~km} \mathrm{~min}^{-1}$. That is, as-spun fibers spun at $V_{\mathrm{s}} \geqq 7 \mathrm{~km} \mathrm{~min}^{-1}$ contain a small amount of the amorphous region corresponding to the $\alpha_{\mathrm{a} 1}$ dispersion and also in as-spun fibers at $V_{\mathrm{s}}=6 \mathrm{~km} \mathrm{~min}^{-1}$, the $\alpha_{\mathrm{a} 2}$ dispersion coexists. The $\alpha_{\mathrm{a} 1}$ dispersion has a smaller $\Delta H_{\mathrm{a}}$ than the $\alpha_{\mathrm{a} 2}$ dispersion, but $T_{\max }$ for the former is higher than that for the latter. This fact strongly suggests that the size of the segment giving $\alpha_{\mathrm{a} 1}$ dispersion ( $\cong$ the 2 nd-order element) is smaller than that for $\alpha_{\mathrm{a} 2}$ dispersion, and the segment movement is rather strongly limited.

Figure 3 reveals that there are two different amorphous regions in PET fibers (the region related to the $\alpha_{\mathrm{a} 1}$ dispersion is denoted as region 1 and the $\alpha_{\mathrm{a} 2}$ dispersion as region 2), and their relative amounts change with spinning velocity. In the region of $V_{\mathrm{a}}>5 \mathrm{~km}$ $\min ^{-1}$, the crystallinity, as determined by X-ray diffraction and differential scanning calorimetry, of the as-spun fibers is nearly constant.

Manabe, Kamide et al. (MK) $)^{9-13}$ assume that the amorphous region is composed of many small particles having different $T_{\max }$ (i.e., $T_{\text {max }}^{\prime}$ in this case). As the viscoelastic behavior of this particle can be represented by the Rouse-Tobolsky-Aklonis theory ${ }^{11}$, then the viscoelastic behavior of the amorphous region of the semicrystalline polymeric solid is represented by the ensembles of those of the particles. Then, $\tan \delta$ of the solid is given by

$$
\tan \delta=\int_{-\infty}^{\infty} F(n) \tan \delta_{\mathbf{R}}(n) \mathrm{d} n
$$

where $\tan \delta_{\mathbf{R}}(n)$ is $\tan \delta$, theoretically calculated by the Rouse-Tobolsky-Aklonis theory for the amorphous region with packing density $n$ of polymeric chain, and $F(n)$ is the normalized packing density distribution function for the amorphous region. $F(n)$ was obtained by solving the integral equation (1) from the observed $\tan \delta$ and theoretical $\tan \delta_{\mathrm{R}}(n)$. Here $n$ 


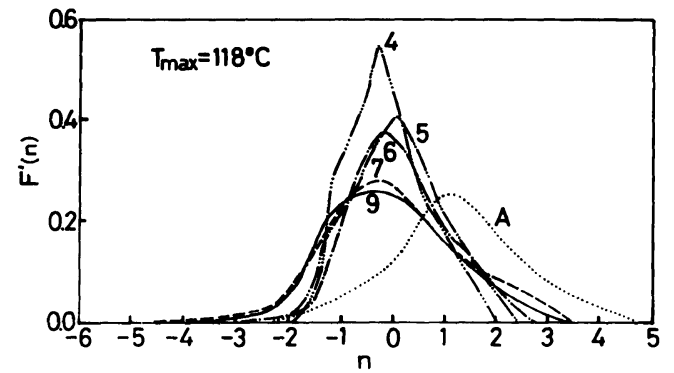

Figure 4. Effect of the spinning velocity $V_{\mathrm{s}}$ on the amorphous packing density distribution curve. The number denotes $V_{\mathrm{s}}$ in $\mathrm{km} \mathrm{min}^{-1}$ and $n$ was taken zero at $T_{\max }=118^{\circ} \mathrm{C}$.

is a parameter representing the packing density of segments for the 2 nd-order element as defined by $\left(T_{\max }^{\prime}-T_{\max }\right) /\left(\Delta T_{1 / 2}\right)_{\mathrm{R}}$, where $T_{\max }$ is the peak temperature of the experimental $\tan \delta$-temperature curve of the sample in the $\alpha_{\mathrm{a}}$ dispersion region, $T_{\max }^{\prime}$, the peak temperature of the 2nd-order element, and $\left(\Delta T_{1 / 2}\right)_{R}$, the half-value width of the $\tan \delta$-temperature curve of the 2 nd-order element. ${ }^{13}$ The $n$ was taken zero at $T_{\max }=118^{\circ} \mathrm{C}$. The elastic modulus fraction $f_{\mathrm{e}}$ contributing to the $\alpha_{\mathrm{a}}$ dispersion can be evaluated by the MK theory. $F^{\prime}(n)$, defined as $F^{\prime}(n)=f_{\mathrm{e}} F(n)$, is more convenient than $F(n)$ to express the change in the detailed structure of the molecular packing in the amorphous region.

Figure 4 shows the packing density function $F^{\prime}(n)$, evaluated according to the MK theory. Here, the single peak approximation was adopted, by neglecting the shoulder in the $\tan \delta$-temperature curve for as-spun PET fibers manufactured at $V_{\mathrm{s}}=4$ and $5 \mathrm{~km} \mathrm{~min}^{-1}$. With an increase in $V_{\mathrm{s}}$, in the range of $V_{\mathrm{s}}>$ $5 \mathrm{~km} \mathrm{~min}^{-1}, F^{\prime}(n)$ becomes broader. The average molecular packing density $\bar{n}$ as defined by $\int_{-\infty}^{\infty} n F^{\prime}(n) \mathrm{d} n / f_{\mathrm{e}}$ becomes smaller as shown in Figure 5, and the $n$ value corresponding to the peak of $F^{\prime}(n)$ (i.e., $\left.F(n)\right)$ decreases with an increase in $V_{\mathrm{s}}$.

Generally, the dyeability of PET fibers with disperse dyes is controlled by the amount of the amorphous region, whose $n$ is not larger

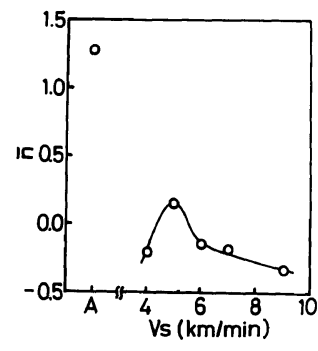

Figure 5. Plot of average packing density $\bar{n}$, defined by $\int_{-\infty}^{\infty} n F^{\prime}(n) \mathrm{d} n / f_{\mathrm{e}}, \quad$ against $V_{\mathrm{s}}\left(\mathrm{km} \mathrm{min}^{-1}\right)$ for as-spun PET fibers. A has the same denotation as in Figure 1.

than a specific value $\left(n_{\max }\right),\left(\equiv \int_{-\infty}^{n_{\max }} F^{\prime}(n) \mathrm{d} n\right) .{ }^{16}$ The $n_{\max }$ depends on the dyeing temperature and time. In this sense, the dyeability of asspun PET fibers should improve with an increase in $V_{\mathrm{s}}$.

\section{REFERENCES}

1. See, for example, D. W. Ihm, and J. A. Cuculo, J. Macromol. Sci.-Rev. Macromol. Chem. Phys., C24, 419 (1984)

2. H. Maeda, Sen-i Gakkaishi, 12, 6 (1956).

3. R. Rosenbaum, J. Appl. Polym. Sci., 7, 1225 (1963).

4. K. Kitamura, S. Kobayashi, and Z. Yoshida, Sen-i Gakkaishi, 27, 501 (1971).

5. J. P. Bell, J. Appl. Polym. Sci., 12, 627 (1968).

6. K. Kitamura, Senshoku Kogyo, 17, 15 (1969).

7. T. Haga and H. Ishibashi, Sen-i Gakkaishi, 29, T-489 (1973).

8. S. Manabe and K. Kamide, Sen-i Gakkaishi, 34, P-70 (1969).

9. S. Manabe, K. Kamide and C. Nakayama, J. Text. Mach. Soc. Jpn., 30, T45 (1977); and also J. Text. Mach. Soc. Jpn., English Edition, 26, 1 (1980).

10. S. Manabe, K. Kamide and C. Nakayama, J. Text. Mach. Soc. Jpn., 30, T55 (1977); and also J. Text. Mach. Soc. Jpn., English edition, 26, 42 (1980).

11. S. Manabe, K. Kamide, and C. Nakayama, J. Text. Mach. Soc. Jpn., 30, T66 (1977); and also J. Text Mach. Soc. Jpn., English Edition, 26, 65 (1980).

12. S. Manabe, K. Kamide, C. Nakayama, and S. Kobayashi, J. Text. Mach. Soc. Jpn., 30, T85 (1977); and also J. Text. Mach. Soc. Jpn., English edition, 27, 10 (1981).

13. S. Manabe and K. Kamide, Polym. J., 16, 375 (1984).

14. K. Kamide, Y. Miyazaki, and H. Kobayashi, Polym. J., 9, 317 (1977).

15. T. Kuriki, K. Kamide, S. Manabe, and M. Iwata, $J$. Text. Mach. Soc. Jpn., 38, T93 (1985).

16. K. Kamide, T. Kuriki, and S. Manabe, Polym. J., 18, 163 (1986). 